\title{
Different Storage-Focused PV-Based Mini-Grid Architectures for Rural Developing Communities
}

\author{
Nicholas Nixon Opiyo \\ Centre for Integrated Energy Research, School of Chemical and Process Engineering, University of Leeds, Leeds, UK \\ Email: Nicholas.Opiyo1@gmail.com
}

How to cite this paper: Opiyo, N.N. (2018) Different Storage-Focused PV-Based Mini-Grid Architectures for Rural Developing Communities. Smart Grid and Renewable Energy, 9, 75-99.

https://doi.org/10.4236/sgre.2018.95006

Received: May 7, 2018

Accepted: May 27, 2018

Published: May 30, 2018

Copyright $\odot 2018$ by author and Scientific Research Publishing Inc. This work is licensed under the Creative Commons Attribution International License (CC BY 4.0).

http://creativecommons.org/licenses/by/4.0/

\section{(c) (i) Open Access}

\begin{abstract}
Impacts of grid architectures on temporal diffusion of PV-based communal grids (community owned minigrids or microgrids) in a rural developing community are modelled and simulated using MATLAB/Simulink and a survey-informed agent-based model (ABM) developed in NetLogo. Results show that decentralised control architectures stimulate minigrid formations and connections by allowing easy expansions of the minigrids as each decentralised PV system within a minigrid is treated equally and determines its own real and reactive power, eliminating the need for communication links. This also reduces the cost of implementing such a system; fewer connections are realized with centralised controls as such systems require high speed communication links which make them both difficult to expand and expensive to implement. Results also show that multi-master operation modes lead to more communal grid connections compared to single-master operation modes because in the former, all distributed PV systems within a communal grid have the same rank and can act as masters or can be operated as combinations of master generators (VSIs) and PQ inverters, allowing for more design flexibility and easy connections from potential customers.
\end{abstract}

\section{Keywords}

Communal Grid, Control, Architecture, DC/AC-Coupling

\section{Introduction}

Modern energy services are fundamental to all three pillars of sustainable development, i.e. social, economic, and environmental. Most energy developments must be implemented in line with all aspects of the development process, e.g. 
energy and communication, energy and health, energy and schools, energy and roads, etc. Energy is therefore a complementary factor to socio-economic development. Electricity, the main form of modern energy, is crucial to industrialization and easy access to it is an indicator of a nation's standard of living. It is estimated that there are about 632 million people in sub-Saharan Africa without access to electricity today and that $84 \%$ of these people reside in rural areas, and that this number is projected to rapidly increase, mainly due to population growth, unless sustained annual investments of about US $\$ 19.1$ billion in electricity generation and distribution are made [1]. Table 1 summarizes the above information.

There are two possible routes to rural electrification i.e., through extensions of existing national utility grids from large central power generation systems or through decentralized systems namely communal grids and stand-alone microgeneration systems. National grid extensions are recommended where the load demands are high enough to make the costs of such investments reasonable. Communal grids are recommended for condensed villages or markets far from national grid lines but with potential economic values to warrant such installations. Stand-alone systems are recommended for isolated homesteads or installations far from existing grid lines, other homesteads, or other installations. The International Energy Agency (IEA) estimates that only 30\% of the people currently without access to electricity in sub-Saharan Africa can be cost-effectively served through national grid extensions due to the sparseness of the rural populations, rough terrains, low economic activities, and low load densities. The remaining $70 \%$ would be most cost-effectively served through decentralized systems, i.e. communal grids (52.5\%) or stand-alone systems (17.5\%) [2] [3] [4] [5] [6]. The modular nature of microgeneration technologies allows for phased

Table 1. Electricity access in 2016 Regional Aggregates [1].

\begin{tabular}{|c|c|c|c|c|}
\hline Region & $\begin{array}{c}\text { Population } \\
\text { without electricity } \\
\text { millions }\end{array}$ & $\begin{array}{c}\text { Electrification } \\
\text { rate } \%\end{array}$ & $\begin{array}{c}\text { Urban } \\
\text { electrification } \\
\text { rate } \%\end{array}$ & $\begin{array}{c}\text { Rural } \\
\text { electrification } \\
\text { rate } \%\end{array}$ \\
\hline Developing countries & 1185 & $79 \%$ & $92 \%$ & $67 \%$ \\
\hline Africa & 634 & $45 \%$ & $71 \%$ & $28 \%$ \\
\hline North Africa & 1 & $99 \%$ & $100 \%$ & $99 \%$ \\
\hline Sub-Saharan Africa & 632 & $35 \%$ & $63 \%$ & $19 \%$ \\
\hline Developing Asia & 512 & $86 \%$ & $96 \%$ & $79 \%$ \\
\hline China & 0 & $100 \%$ & $100 \%$ & $100 \%$ \\
\hline India & 244 & $81 \%$ & $96 \%$ & $74 \%$ \\
\hline Latin America & 22 & $95 \%$ & $98 \%$ & $85 \%$ \\
\hline Middle East & 18 & $92 \%$ & $98 \%$ & $78 \%$ \\
\hline $\begin{array}{c}\text { Transition economies \& } \\
\text { OECD }\end{array}$ & 1 & $100 \%$ & $100 \%$ & $100 \%$ \\
\hline WORLD & 1186 & $84 \%$ & $95 \%$ & $71 \%$ \\
\hline
\end{tabular}


project implementations, enabling households and communities to initiate the modest power generation programs, and to modify their systems according to their changing energy needs. Depending on local resources, capacities, designs and technologies used, microgeneration systems could provide the final solutions to rural electrification in many developing nations and entrench green economies in the process. In fact, it is estimated that there will be almost 400 TWh of installed microgeneration capacity by 2030 , about $40 \%$ of new installed capacities towards universal electrification in developing nations [1].

Many factors influence choices of technologies used in rural electrification, the main ones being availability of resources, demand, investment costs, and local socio-political and cultural environments. Different modelling tools and techniques have been applied in planning rural electrification paths in many countries. However, these often view this problem as a question of expansion of grid coverage through extensions of existing transmission and distribution lines from central power generation stations and seldom address the unique and regionally-specific challenges presented by many developing nations [7] [8] [9]. In most of sub-Saharan Africa for example, grid electricity is often unreliable, plagued with frequent blackouts, poor maintenance, and low quality of service. In these regions, expansions of the national grids often result in further strain on the systems and thus in further reduction in the quality of services provided to those already grid-connected [10]. Bhattacharyya and Timilsina point to models that can capture a developing nation's unique context as a key input for future policy formulation, while Urban et al. point to the lack of focus to date on off-grid technologies based on locally available renewable energy resources and on the prevailing socio-economic and cultural factors [11] [12].

Development of electricity delivery infrastructures are path-dependent, meaning, each development decision and step affects subsequent steps, and the final outcome. Human actors are therefore the most important variables in any energy development plan as their decisions affect the way a system evolves. Proper policy-planning tools are therefore required to guide decision-makers on least-cost rural electrification topologies. In this work an agent-based model $(\mathrm{ABM})$ is developed as tool for evaluating impacts of network architectures on temporal diffusion of PV-based communal grids in a rural developing community. The model takes into account the complexities and limitations of solar electricity microgeneration technologies, decisions by human actors, geographical factors, and interactions between the three factors in order to capture the overall macro-effects of different micro-decisions in a virtual world; ABMs seek to model individual entities within a complex system and the rules that govern the interactions of the entities within the system, to capture the overall effect of such interactions. The novelty of the model developed in this work is that it simultaneously captures how technical and socio-economic factors affect temporal diffusion of PV-based communal grids in a typical rural developing community. Specifically, the model simulates how different communal grid architectures af- 
fect costs, ease of connections, and scalability.

\section{Overview of PV-Based Communal Grids}

A PV-based communal gridis defined as a locally confined and independently controlled electric power grid in which a distribution architecture integrates distributed loads and distributed energy resources-i.e. local distributed PV systems and energy storage devices-which allows the communal grid to operate in both islanded and utility grid-connected modes.Communal grids are operated in islanded mode when they are situated far from existing utility transmission networks, or if the owners of the grid prefer independence of their own power source. On the other hand, communal grids can be utility-grid connected to improve system economics, to improve operations, and to improve stability, while the utility grid gets to enjoy improved availability, improved stability, and reduced conductor sizes. For a successful interfacing of communal grids to utility grids, converters/inverters should allow net metering (bi-directional flow of power), peak shaving, advanced communications and control, and fast demand response.

\subsection{Control Structures}

Inverters are used to interface communal grids with utility grids and can be classified according to modes of operation as PQ or V-f (also known as voltage source inverter (VSIs)). A PQ inverter controls the real (P) and reactive $(\mathrm{Q})$ power by adjusting the magnitude of the output real and reactive current. It therefore operates as a voltage controlled current source [13]. A voltage source inverter controls the voltage (V) and frequency (f) at the output terminal, and thus operates as a voltage source [13] [14]. The mode of an inverter operation is chosen depending on a communal grid's architecture and control strategy, and may change depending on whether the communal grid is islanded or grid-connected. Unlike synchronous generators, inverters do not have rotors and thus no natural connection between frequency and active power. To achieve stable operation with multiple distributed PV systems, the inverters are controlled so that they mimic the characteristics of synchronous generators with P-f and Q-V droop controls [15]. In P-f and Q-V droop controllers for a PQ inverter, $\mathrm{P}$ and $\mathrm{Q}$ injections are changed proportionally to frequency and voltage deviations, respectively. On the other hand, P-f and Q-V droop controllers of a VSI changes the frequency and the voltage proportionally to $\mathrm{P}$ and $\mathrm{Q}$ deviations [18]. These relationships are modelled as [13] [14] [15]:

$$
\begin{aligned}
& P(f)=P_{0}-\left(f_{\text {set }}-f\right) k_{f} \\
& Q(V)=Q_{0}-\left(V_{\text {set }}-V\right) k_{v}
\end{aligned}
$$

where $P_{0}$ is the power delivered by the inverter at set point frequency $f_{\text {set }}, k_{f}$ is the gradient of the droop, which determines how much the active power $P$ will change in response to a change in frequency $f, Q_{0}$ is the reactive power delivered/consumed by the inverter at set point voltage $V_{\text {set }}$ and $k_{v}$ is the gradient 
of the droop, which determines how much the reactive power $Q$ will change in response to a change in voltage $V$.

The two general control structures used in communal grids are centralised control and decentralised controls [16] [17]. In centralised control, a central controller (CC) determines the operating points of the communal grid and sends this information via communication systems to some or all the distributed PV systems and potentially to some of the loads throughout the communal grid network. In decentralised control, a virtual communication system independently determines the operating points of each decentralised PV system and load within the communal grid network, effectively eliminating the need for communication links and thus increasing system reliability as well as reducing cost. This enables easy and cost-effective expansion of the communal grid by enabling decentralised PV systems and loads to have plug-and-play capabilities. The two configurations can be implemented under two main modes of operation, i.e., master slave or multi master [18].

\subsubsection{Master Slave (Single Master) Operation}

In master slave mode of operation, all the inverters in the network operate in PQ mode when the communal grid is connected to the utility grid, since the latter controls the voltage and frequency. In islanded mode, a single master inverter switches to voltage source (VSI) mode to provide the voltage and frequency references while the remaining distributed PV systems continue to operate in PQ mode [13]. The system can operate in either a centralised configuration or in a decentralised configuration. In centralised configuration, a single VSI acts as the voltage and frequency reference while all the other inverters operate in PQ current source mode. The load is equally shared across each inverter such that the current produced from the master is used as a reference for the PQ inverters. The operating current is communicated to them in real time. This configuration is therefore only possible with high speed communication links and is thus difficult to expand [19]; it is therefore not recommended for communal grids which require modularity in design. Figure 1 shows a centrally controlled master slave operation [14] [20].

In decentralised configuration every decentralised PV system, including the master has a built-in generation profile determined by P-f and Q-V droop curves. Each unit therefore determines its own real and reactive power. A single pilot machine is used to set a pilot waveform. The master VSI sets the voltage and frequency based on its droop and the PQ inverters determine the active power from the system frequency set by the master VSI and the reactive power from the local voltage measurements [21]. The pure droop system gives equal priority to all distributed PV systems within the network and enables easy expansion of the system. In grid-connected mode, the utility grid sets the frequency (with very little variation) ensuring constant power output while in islanded mode, the master VSI uses droops to control the frequency and voltage of the network [21]. 


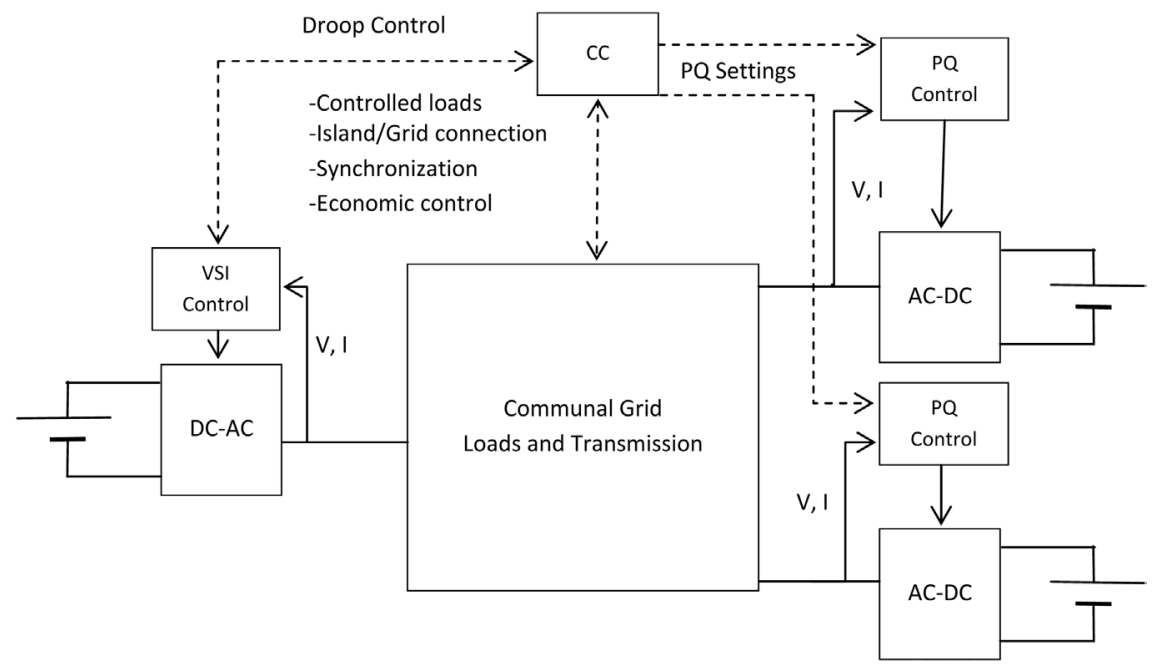

Figure 1. A Centrally controlled single master communal grid.

\subsubsection{Multi-Master Operation}

In multi-master mode of operation, all distributed PV systems within a communal grid can act as masters or can be operated as combinations of master generators (VSIs) and PQ inverters [13]. This mode shares many aspects with single master operation and can also be operated in centralised or decentralised configuration. The principle is almost identical to the centrally control single master system. One advantage is that battery interfaced VSIs can be distributed throughout the network [22]. Figure 2 shows a centrally controlled VSI-PQ multi master operation [20] [23]. Compared with single master, the centralised control for multi master requires a higher level of communication between master VSIs. This adds complexity, although it does have the advantage of built-in redundancy as the system will continue to operate if one of the master VSIs goes off-line [16].

Decentralised configuration for multi master is almost identical to the single master mode. All distributed PV systems can regulate their power outputs in grid-connected and islanded modes by using individual droop controls. Here also, a single pilot machine is used to set a pilot waveform. Multi master pure droop systems are well suited to systems with multiple integrated, renewable energy/storage generators spread throughout a communal grid. When implemented in this way the load will be shared equally across all distributed PV systems [23]. The dynamic response of the inverters was neglected given the limited scope of the paper; the paper focuses more on network architectures than on control [30].

\section{Modelling PV-Based Communal Grids}

Different communal grid architectures, revolving about energy storage, are modelled and simulated in MATLAB/Simulink to determine the most cost-effective option for a given transmission and distribution network. Each system modelled below comprises of $4 \mathrm{PV}$ arrays, each rate at $100 \mathrm{~kW}$ at $1000 \mathrm{~W} / \mathrm{m}^{2}$ 


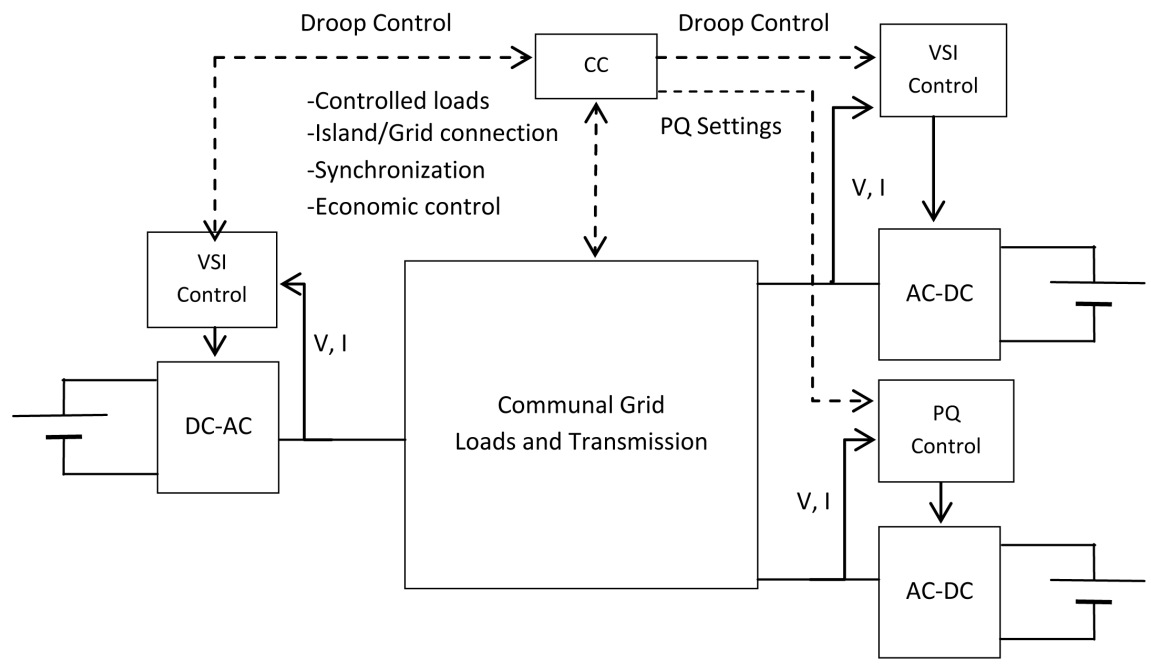

Figure 2. A centrally controlled combined VSI-PQ multi master communal grid.

radiation and $25^{\circ} \mathrm{C}$; each array consists of 66 parallel strings, each comprising 5 PV 330 SunPower (SPR-305-WHT-D) modules connected in series $(66 \times 5 \times$ $305.2=100.7 \mathrm{~kW})$. Each array is connected to a $5 \mathrm{kHz}$ boost DC-DC converter with maximum power point tracking (MPPT) and charge-controlling capabilities. Each converter uses the perturb-and-observe method to extract maximum voltage (273V DC) from each array and then boosts it to $500 \mathrm{~V}$ DC. For utility grid interfacing, a DC-AC inverter inverts the DC bus voltage to $260 \mathrm{~V} \mathrm{AC}$, while keeping a unity power factor. The inverter uses two control loops: one which regulates DC link voltage to $+/-250 \mathrm{~V}$ and an internal control loop which regulates active and reactive current. Active current reference is the output of the DC voltage external controller while reactive current reference is set to zero to maintain unity power factor. A 40-kvar capacitor bank is used to filter harmonics produced by the inverter. The inverter is connected to the utility grid through a $400-\mathrm{kVA} 260 \mathrm{~V} / 25 \mathrm{kV}$ step-up transformer.

\subsection{DC-Coupled Communal Grids}

Communal grids can be classified as ether DC-coupled or AC-coupled depending on the common bus voltage. A grid using a DC bus avoids many of the power conversion steps required when using an AC bus leading to higher energy efficiency and cost-saving. Traditionally, AC enabled efficient voltage transformation and high-voltage power transmission over long distances. Recently however, technology advances have led to highly efficient AC/DC and DC/DC converters, making high-voltage DC long-distance bulk power transmission more efficient [24]. Due to lower power and energy rating, stability issues are more prevalent in communal grids than in utility grids. Analyses of stability issues in AC-coupled communal grids follow the same concepts as with utility grids, i.e.:

- Voltage and frequency values need to both be regulated through active and reactive power control; 
- If a decentralised power source is a traditional synchronous generator with an AC output, and is connected directly to the utility grid without power electronic interfaces, stability is controlled through the machine shaft's torque and speed control.

In DC systems, there are no reactive power interactions which suggest that there are few stability issues; system control seems to be oriented towards voltage regulation only.

\subsubsection{DC-Coupled Communal Grid with Decentralised Storage} In these systems generated DC voltage by the PV systems is distributed throughout the communal grid in the DC form. Inverters are therefore not required for common bus connections. Each DC-DC converter for each PV system is necessary for maximum power point tracking (MPPT) and for charge controlling of the storage system. Figure 3 shows a Simulink model used to implement a DC-coupled communal grid with decentralised storage. Each Converter is connected to a decentralised lead acid battery bank rated at $1040 \mathrm{Ah}$, with a $25 \%$ depth of discharge (DOD), and 3 days of autonomy. The battery is then connected to a $500 \mathrm{~V}$ DC common bus. The load across each converter is stochastically allocated between $10 \mathrm{~kW}$ and $25 \mathrm{~kW}$, based on Kendu Bay data and potential number of households served by each array [25]. If the DC bus voltage is kept stable at a certain level, future connections to the communal grid are easy as no modifications to the interfacing inverter are necessary.

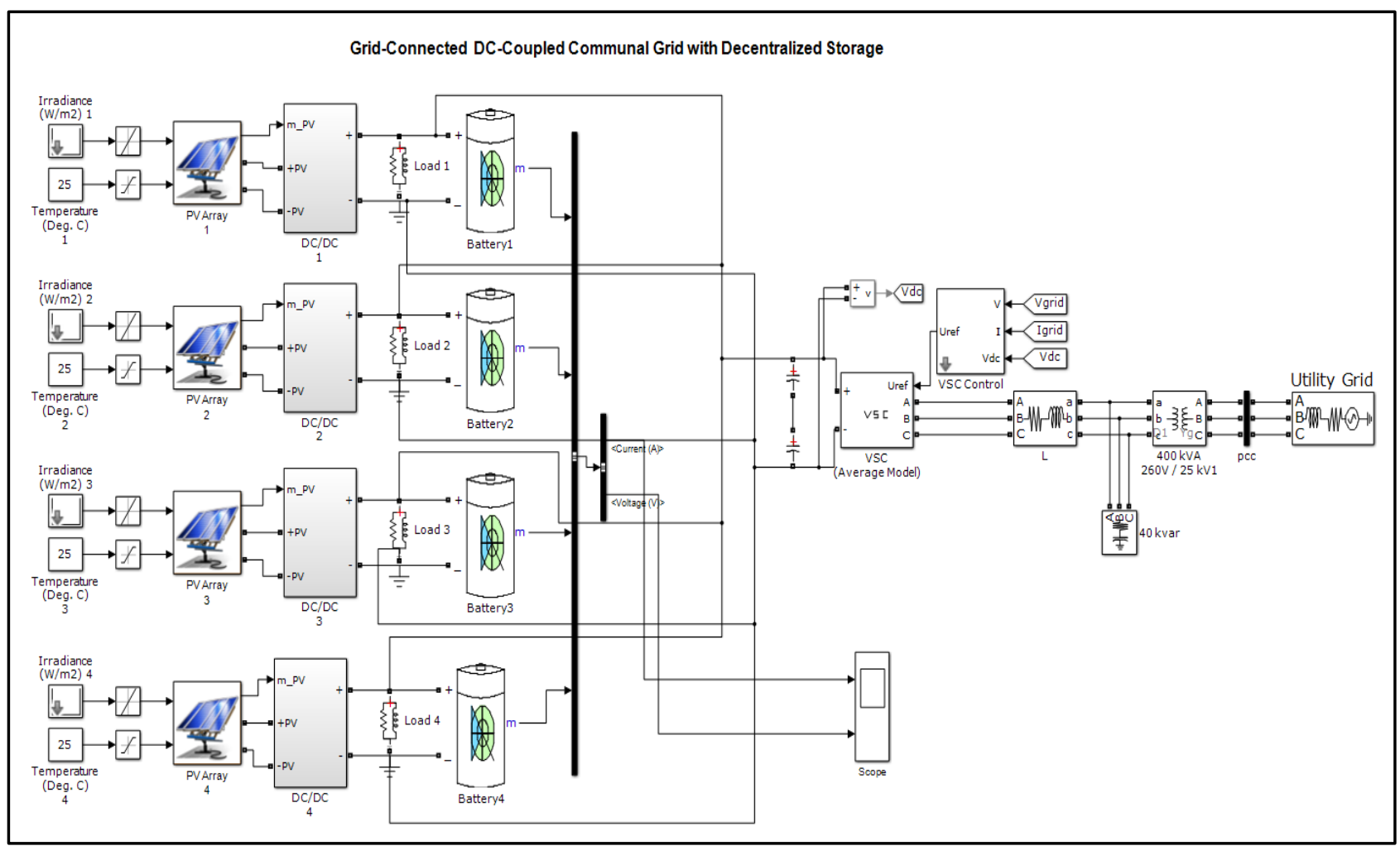

Figure 3. Simulink Model of a DC-Coupled Communal Grid with Decentralised Storage. 


\subsubsection{DC-Coupled Communal Grid with Centralised Storage}

Figure 4 shows a Simulink model used to implement a DC-coupled communal with centralised storage. These systems are like DC-coupled systems with decentralised storage, with the exception being that the storage system is now centralised. Each DC-DC converter for each PV system is still necessary for maximum power point tracking, however, the task of charge controlling is now performed by an appropriately sized central converter connected to the central storage system. Future connections to the communal grid are complicated by the fact that each time the storage capacity is increased to meet the increased demand, a new appropriately sized DC-DC charge controller must be purchased for the network. Here, the battery bank capacity is increased to $4160 \mathrm{Ah}$ while the DOD is kept at $25 \%$. The days of autonomy is also kept at 3. A DC link capacitor is used to connect the grid interfacing VSI is connected to the central charge controller.

\subsection{AC-Coupled Communal Grids}

Majority of appliances require $\mathrm{AC}$ power to operate and $\mathrm{AC}$ is the main form of power transmitted and distributed around the world. It is therefore important to model AC coupled-networks, and compare them to DC-coupled networks.

\subsubsection{AC-Coupled Communal Grid with Decentralised Storage}

Figure 5 shows a Simulink model used to implement an AC-coupled communal grid with decentralised storage. In these systems generated DC voltage by the PV systems is first inverted into AC form before being distributed throughout the

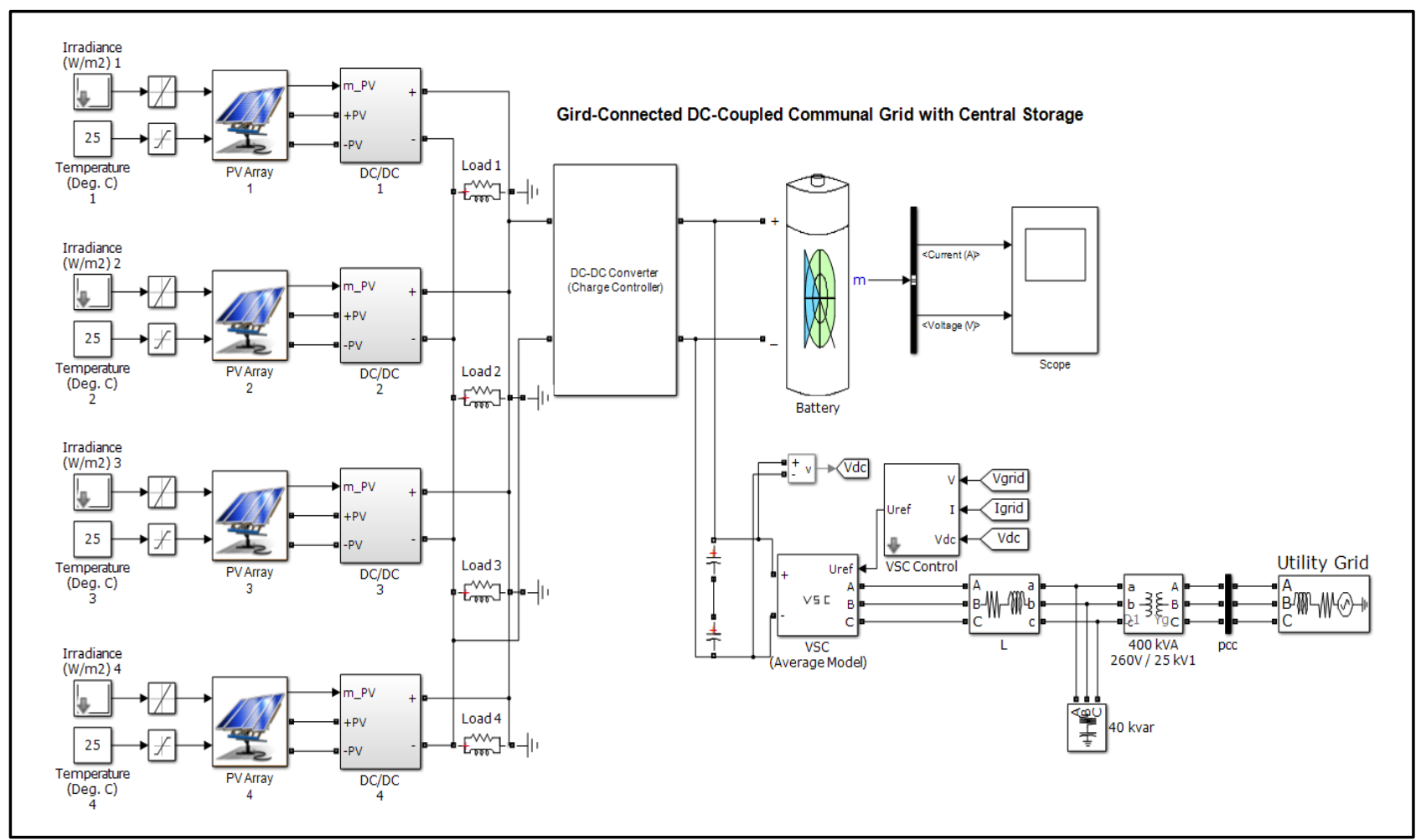

Figure 4. Simulink model of a DC-coupled communal grid with centralised storage. 


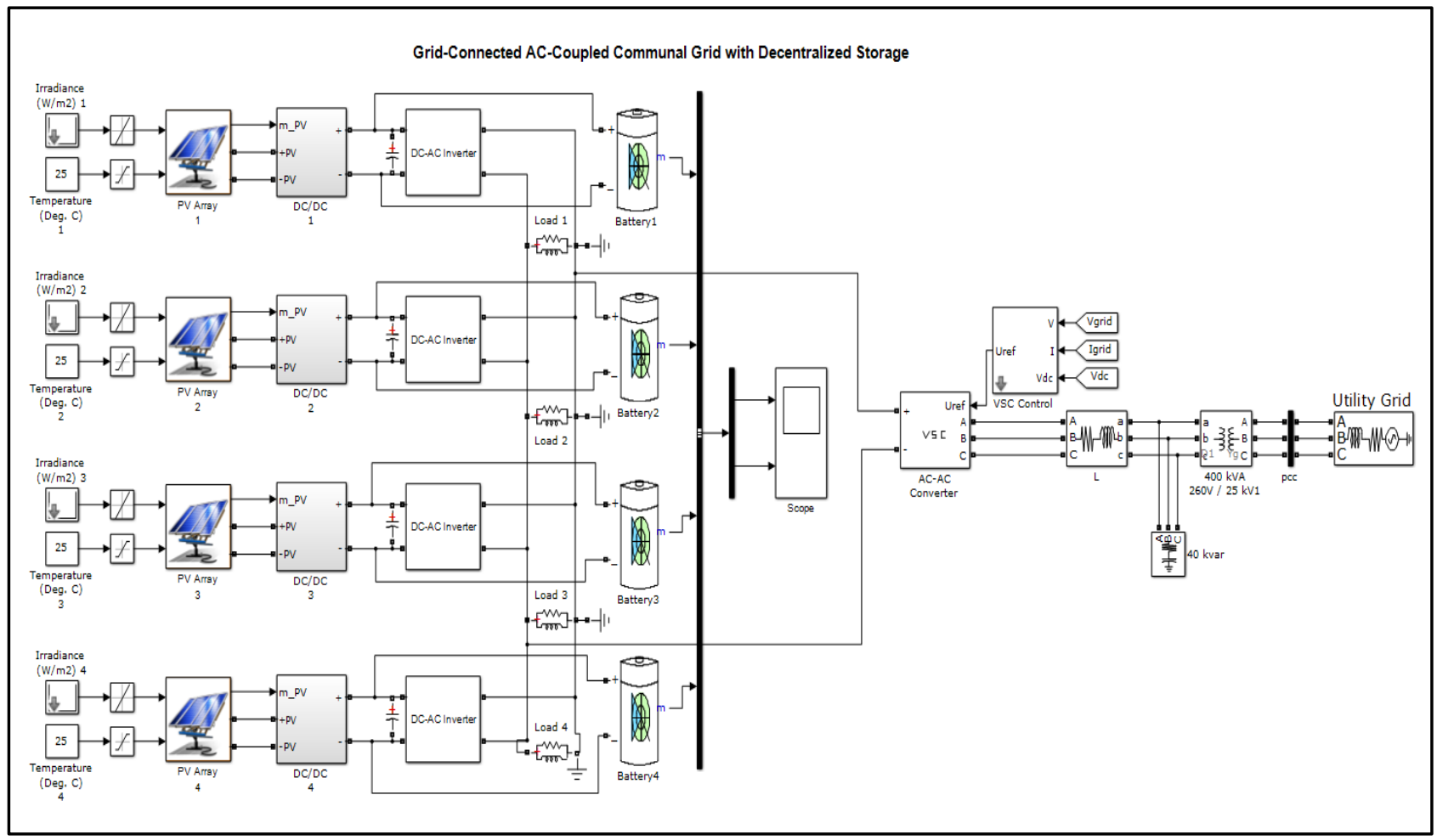

Figure 5. Simulink model ofan AC-coupled communal grid with decentralised storage.

network. Due to decentralised storage, each household has its own DC-AC inverter for connection to the common AC bus. A decentralised control system is used to set the network voltage amplitude and frequency. The system works by using a virtual communication system to independently determine the operating points of each decentralised PV system and load within the communal grid network, effectively eliminating the need for communication links and thus increasing system reliability as well as reducing cost [26]. This enables easy and cost-effective expansion of the communal grid by enabling decentralised PV systems and loads to have plug-and-play capabilities. Every decentralised PV system, including the master has a built-in generation profile determined by P-f and Q-V droop curves. Each unit therefore determines its own real and reactive power, eliminating the need for communication networks in the process. The master VSI sets the voltage and frequency based on its droop and the PQ inverters determine the active power from the system frequency set by the master VSI and the reactive power from the local voltage measurements [21]. Even though here the common bus voltage is in AC form, it is at a different frequency and voltage amplitude from the utility grid, another AC-AC converter is therefore needed for grid interfacing. Future connections to the communal grid are easy as no modifications to the interfacing inverter are necessary.

\subsubsection{AC-Coupled Communal Grid with Centralised Storage}

Figure 6 shows a Simulink model used to implement an AC-coupled communal grid with centralised storage. A bi-directional AC-DC inverter with charge 


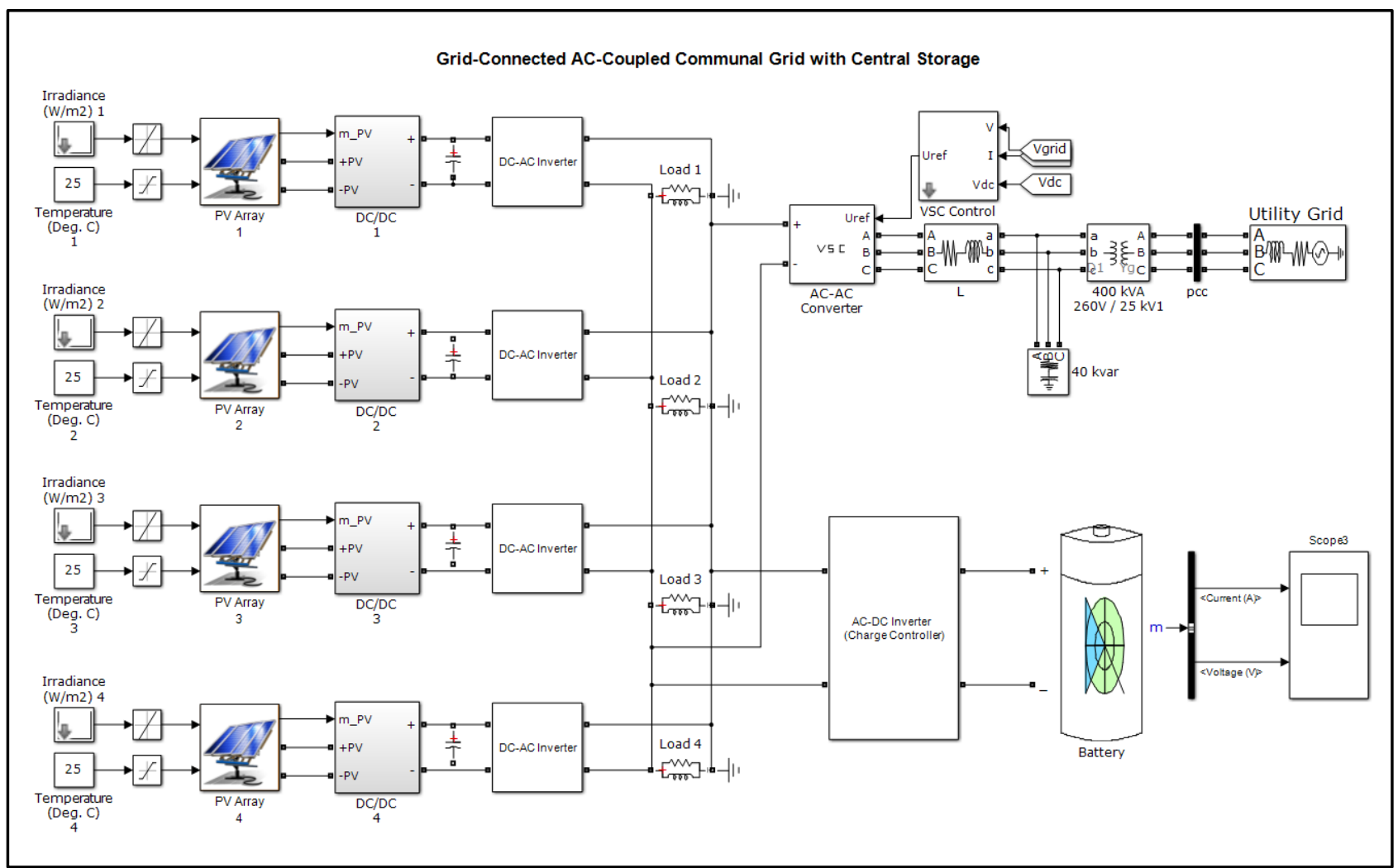

Figure 6. Simulink model of an AC-coupled communal grid with centralised storage.

controlling capabilities is used to connect the central energy storage system to the common AC bus. Since the central inverter is large compared to the individual array inverters, it also acts as master VSI for setting up reference line voltage amplitude and frequency while other inverters function as PQ inverters. Future connections to the communal grid are complicated by the fact that each time the storage capacity is increased to meet the increased demand, a new appropriately sized AC-DC inverter must be purchased for the network.

\section{Agent-Based Model (ABM)}

Simulated data from the Simulink models are fed into an agent based model (ABM)developed in NetLogo, to simulate effects of control architectures on temporal diffusion of $\mathrm{PV}$-based communal grids in a rural developing community, with the main driving factor being the cost of setting up and connecting to a given control architecture. NetLogo is a multi-agent programmable language that was authored by Uri Wilenskey and developed at Northwestern University [27]. It was chosen for this work because it is widely accepted by scholars as one of the best environments for socio-economic agent-based modelling [28]. Moreover, it is free to download and use. Figure 7 shows a graphical user interface of the NetLogo model.

The following agents are created in the model:

1) A representation of the environment and the solar potential in it, 


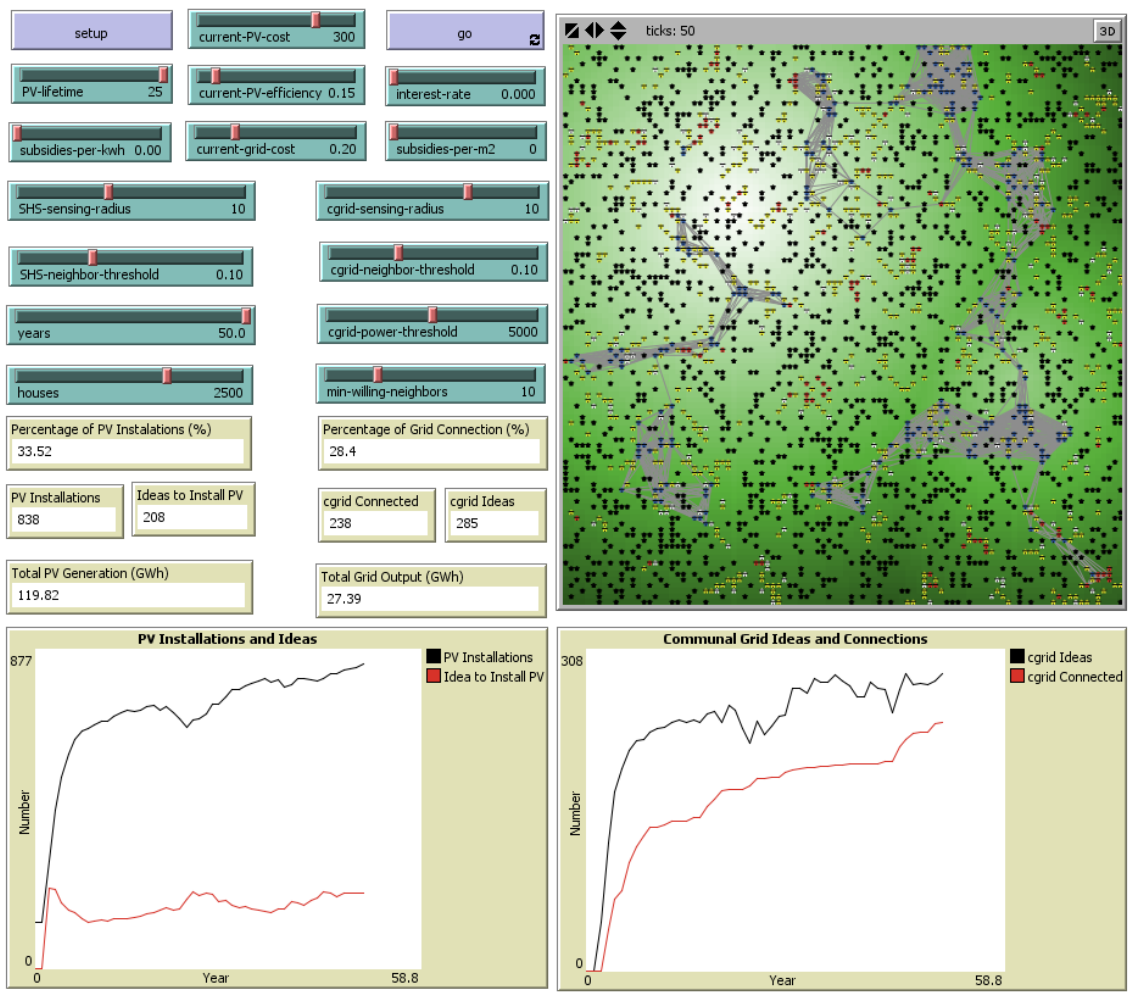

Figure 7. NetLogo graphical user interface.

2) The populations in it that require electricity,

3) PV seeds that would use the environment to produce electricity,

4) Links which are used by households with PV to connect to communal grids, and

5) A central observer or stakeholder who determines the strategies and preferences for PV diffusions.

Through these agents and the rules created for their interactions, the model is used to simulate the way decisions and preferences by human actors affect PV diffusion. Kendu Bay survey data are used to inform the model [25]. Table 2 shows parameters used in the model:

A household without PV would consider installing PV if

$$
L U C E_{P V}<C_{A / k W h}
$$

where $C_{A / k W h}$ is avoided cost per $\mathrm{kWh}$, i.e., the prevailing national grid electricity cost per $\mathrm{kWh}$ and equals $\$ 0.20 / \mathrm{kWh}$ as per current Kendu Bay rates [25], while $L U C E_{P V}$ is the levelised unit cost of delivered electricity and is given by

$$
L U C E_{P V}=\frac{A L C C_{P V}}{W_{p} \times E H F S \times 365 \times C U F}
$$

where $W_{p}$ is the rated peak Watt capacity of the PV module and is based on a household's activity profile and power demand [16], EHFS is the equivalent hours of full sunshine per day and equals 8 [26], CUF is the capacity utilization factor which incorporates non-utilization and outages of systems due to various 
Table 2. Parameters used in the NetLogo model.

\begin{tabular}{|c|c|c|}
\hline$\underline{\text { Parameter }}$ & Value and Unit & $\underline{\text { Description }}$ \\
\hline$C_{A / k W h}$ & $\$ 0.20 / \mathrm{kWh}$ & Avoided Cost \\
\hline EHFS & $8 \mathrm{Hrs}$ & Equivalent hours of full sunshine per day \\
\hline$C U F$ & 0.9 & Capacity utilization factor \\
\hline$C_{0 P V}$ & $\$ 1.40 / \mathrm{Wp}$ & Capital cost of the PV module \\
\hline$C_{\text {obatt }}$ & $\$ 0.95 / \mathrm{Ah}$ & Capital cost of the battery \\
\hline$C_{0 c c}$ & $\$ 28.50$ & Capital cost of the charge controller \\
\hline$C_{\text {0appl }}$ & \$75/household & Capital cost of appliances \\
\hline$C_{O \& M}$ & $\$ 2.50 /$ year & Operations and maintenance cost \\
\hline$i$ & $12 \%$ & Discount rate \\
\hline$C_{O P V_{C G}}$ & $\$ 1,400 / \mathrm{kWp}$ & Capital cost of the PV array \\
\hline$C R F_{p с u}$ & 0.2774 & Capital recovery factor of the power conditioning unit \\
\hline$C_{0 d n}$ & $\$ 2500 / \mathrm{km}$ & Capital cost of the power distribution network \\
\hline$C_{0 s c}$ & \$125/household & $\begin{array}{c}\text { Capital cost of service connections including internal } \\
\text { wiring and appliances }\end{array}$ \\
\hline$L$ & $1 \mathrm{~km}$ & Length of the distribution network \\
\hline$C R F_{p d n}$ & 0.1770 & Capital recovery factor of the distribution network \\
\hline$R$ & $\$ 1400 / \mathrm{kWp}$ & Benchmark unit cost of the communal grid \\
\hline$b$ & 0.95 & $\begin{array}{l}\text { Scale factor for incorporating cost reduction in overal } \\
\text { cost of the communal grid }\end{array}$ \\
\hline
\end{tabular}

reasons and equals 0.9 based on Kendu Bay survey data [25], and $A L C C_{P V}$ is the annualized life cycle cost which is calculated by summing up the cost of all of its individual components, i.e. the module, battery, charge controller, and appliances multiplied by their respective capital recovery factors plus operations and maintenance costs. It is expressed as

$$
\begin{aligned}
A L C C_{P V}= & \left(C_{0 P V} \times C R F_{P V}\right)+\left(C_{0 b a t t} \times C R F_{b a t t}\right)+\left(C_{0 c c} \times C R F_{c c}\right) \\
& +\left(C_{0 a p p l} \times C R F_{\text {appl }}\right)+C_{O \& M}
\end{aligned}
$$

where $C_{0 P V}$ is the capital cost of the PV module and is set at $\$ 1.40 / \mathrm{Wp}$ based on Kenya's PV costs, $C_{0 b a t t}$ is the capital cost of the battery and is set at $\$ 0.95 / \mathrm{Ah}$ based on the price of a typical $48 \mathrm{~V} 100 \mathrm{Ah}$ battery in Kenya, $C_{0 c c}$ is the capital cost of the charge controller and is set at $\$ 28.50$ as per Kenyan rates, and $C_{0 a p p l}$ is the capital cost of appliances and is averaged at $\$ 75$ per household based on typical load profiles of $95 \%$ of households with PV systems in Kendu Bay [25]. $C R F_{P V}, C R F_{b a t t}, C R F_{c c}$, and $C R F_{a p p l}$ are the capital recovery factors of the PV module, the battery, the charge controller, and appliances, respectively, while $C_{O \& M}$ is the operations and maintenance cost and is set at $\$ 2.50 /$ year based on Kendu Bay survey data [25].

Capital recovery factor $(C R F)$ is calculated using the formula 


$$
C R F=\frac{i(1+i)^{n}}{(1+i)^{n}-1}
$$

where $i$ is the discount rate and is set at $12 \%$ based on average Kenya's central bank rates over the past 12 months, while $n$ is the life of the particular component being considered, i.e. 25 years for PV modules/arrays, 5 years for batteries, 5 years for converters/inverters/charge controller, and 10 years for appliances (cumulative load). Based on these figures, $C R F_{P V}=0.1339, C R F_{\text {batt }}=0.2774$, $C R F_{c c}=0.2774$, and $C R F_{c c}=0.1770$.

For a communal grid consisting of $N$ households, levelised unit cost of delivered electricity $\left(L U C E_{C G}\right)$ is given by

$$
L U C E_{C G}=\frac{A L C C_{C G}}{P V_{C G} \times E H F S \times 365 \times C U F}
$$

where $P V_{C G}$ is the capacity of the communal grid ( $\mathrm{PV}$ array) in $\mathrm{kWp}$ and is based on the activity profiles of all households connected to the communal grid, EHFS is the equivalent hours of full sunshine per day and equals 8, CUF is the capacity utilization factor which incorporates non-utilization and outages of systems due to various reasons and is maintained at 0.9 , and $A L C C_{C G}$ is the annualized life cycle cost of the communal grid and is given by

$$
\begin{aligned}
A L C C_{C G}= & {\left[\left(C_{0 P V_{C G}} \times C R F_{P V}\right)+\left(C_{0 b a t t C G} \times C R F_{b a t t}\right)+\left(C_{0 p c u} \times C R F_{p c u}\right)\right] } \\
& \times\left[P V_{C G} \times R\right]^{b}+\left[\left(C_{0 d n} \times L\right)+\left(C_{0 s c} \times N\right)\right] \\
& \times C R F_{p d n}+C_{O \& M_{C G}}
\end{aligned}
$$

where $C_{0 P V_{C G}}$ is the capital cost of the PV array and associated mounting structures and is set at $\$ 1400 / \mathrm{kWp}, C_{0 \text { CGrid_batt }_{\text {_t }}}$ is the capital cost of the battery bank and associated structures and equals $\$ 0.95 / \mathrm{Ah} \times N, C_{0 \text { p } u}$ is the capital cost of the power conditioning unit (power electronics) and equals $\$ 28.50 \times N$, $C R F_{p c u}$ is the capital recovery factor of the power conditioning unit and equals $0.2774, C_{0 d n}$ is the capital cost of the power distribution network per $\mathrm{km}$ and equals $\$ 2500$ for Kendu Bay, $C_{0 s c}$ is the capital cost of service connections including internal wiring and appliances per household serviced and equals \$125 based on similar networks in Kenya, $L$ is the length of the distribution network in $\mathrm{km}$ and is initially set at $1 \mathrm{~km}$ for a neighbourhood radius of $500 \mathrm{~m}, C R F_{p d n}$ is the capital recovery factor of the distribution network including the service connections and is calculated to be $0.1770, C_{O \& M_{C G}}$ is the cost of operating and maintaining the communal grid and is estimated to be $\$ 2.50 \times N, R$ is the benchmark unit cost of the communal grid and is set at $\$ 1400 / \mathrm{kWp}$, and $b$ is a scale factor for incorporating cost reduction in overall cost of the communal grid, without the power distribution network $(p d n)$, due to bulk purchasing of the components used in the grid [26]. Its effect is uniformly distributed over all components of the communal grid, minus the distribution network. It is set at 0.95 . 
Once cost has been determined, PV is installed by a household if

$$
\frac{H_{P V / S R}}{H_{\text {Total } / S R}} \times 100>T_{S R}
$$

where $H_{P V / S R}$ is the number of households with PV within a given sensing radius $(S R)$ or neighbourhood, $H_{\text {Total } / S R}$ is the total number of households within the same sensing radius, and $T_{S R}$ is the neighbourhood threshold. For Kendu Bay, the initial sensing radius is set at $500 \mathrm{~m}$ based on population distribution; a sensing radius below $500 \mathrm{~m}$ limits impacts of neighbourhood influence on a household to one's own clan, based on homestead and farm distributions [25]. The initial neighbourhood threshold is set at 10\%; simulation results showed that values below $10 \%$ showed no impact (influence) on PV diffusion.

The size of the installed PV system by the household is given by

$$
\begin{aligned}
& P V\left(\mathrm{~W}_{\mathrm{p}}\right) \\
& =\left(\frac{P \times h}{\eta_{\text {inv }(P V)} \times \eta_{\text {batt }(P V)} \times \eta_{c c} \times\left(1-f_{\text {temp }}\right) \times\left(1-f_{\text {dust }}\right) \times\left(1-f_{\text {mismatch }}\right) \times E H F S}\right)
\end{aligned}
$$

where $P$ is the household's power load, $h$ is the number of hours the load is operated per day, $\eta_{c c}$ is the charge controller efficiency, $f_{\text {temp }}, f_{\text {dust }}$, and $f_{\text {mismatch }}$ are the losses in PV module due to cell temperature, dust, and mismatch amongst several cells due to shadow and other factors, and EHFS is the equivalent hours of full sunshine. $P$ is calculated from a list of stochastically allocated appliances based on active occupancy, time of the day, and day of the week [29].

The required battery capacity for the household is given by

$$
\operatorname{Batt}(\mathrm{A} \cdot \mathrm{h})=\left(\frac{P \times h}{\eta_{i n v(P V)} \times V \times M D o D \times \eta_{b a t t(P V)}}\right) \times D
$$

where $V$ is the operating voltage of the battery, $\eta_{i n v(P V)}$ is the efficiency of inverter, $M D o D$ is the maximum depth of battery discharge, $\eta_{\text {batt }(P V)}$ is the charging/discharging efficiency of the battery, and $D$ is the days of autonomy.

To be allowed to join a communal grid, a household must have electricity needs beyond lighting and must demonstrate this by having installed PV of a given minimum capacity (power-threshold), which is set at $2 \mathrm{KWp}$. They must also be within a given sensing radius of other houses with $\mathrm{PV}$ that meet the power-threshold. A household will join a communal grid if

$$
\frac{H_{C G / S R}}{H_{\text {Total } / S R}} \times 100>T_{S R}
$$

where $H_{C G / S R}$ is the number of households with $\mathrm{PV}$ within the sensing radius that meet the power-threshold and $H_{\text {Total/SR }}$ is the total number of households within the same sensing radius.

For a communal grid consisting of $N$ households, the total PV capacity is given by 


$$
\begin{aligned}
& P V_{C G}\left(\mathrm{~kW}_{\mathrm{p}}\right) \\
& =\left(\frac{P \times h}{\eta_{\text {inv }(C G)} \times \eta_{\text {batt }(C G)} \times \eta_{c c} \times\left(1-f_{\text {temp }}\right) \times\left(1-f_{\text {dust }}\right) \times\left(1-f_{\text {mismatch }}\right) \times D F \times E H F S}\right)
\end{aligned}
$$

where $\eta_{i n v(C G)}$ is the cumulative efficiency of inverters used in the communal grid, $\eta_{\text {batt }(C G)}$ is the cumulative charging/discharging efficiency of the batteries used in the communal grid, and $D F$ is the diversity factor, ratio of the sum of all individual peak loads to the maximum load of the entire communal grid.

The total battery capacity required for the communal grid is given by

$$
\operatorname{Batt}_{C G}(\mathrm{~A} \cdot \mathrm{h})=N \times\left(\frac{P \times h}{\eta_{i n v(C G)} \times V \times M D o D \times \eta_{\text {batt }(C G)} \times D F}\right) \times D
$$

Generally, $P V_{C G}\left(\mathrm{~kW}_{\mathrm{p}}\right)$ should equal $N \times P V\left(\mathrm{~W}_{\mathrm{p}}\right)$, while $\operatorname{Batt}_{C G}(\mathrm{~A} \cdot \mathrm{h})$ should equal $N \times \operatorname{Batt}(\mathrm{A} \cdot \mathrm{h})$; the deficit should be evenly distributed between the households forming the communal grid. i.e., they may need to increase the sizes of their installed systems.

\section{Results and Discussion}

Figure 8 shows a comparison of the irradiances hitting each of the 4 PV arrays shown in all simulations within 3 seconds (duration of simulation). Variations in irradiances have been included to account to mimic real environmental conditions. In PV 11,000 W/m $/ \mathrm{m}^{2}$ radiation hits the array for 0.5 seconds before falling sharply to $50 \mathrm{~W} / \mathrm{m}^{2}$ for 2 seconds, before rising again to $1000 \mathrm{~W} / \mathrm{m}^{2}$ for the remainder of the simulation. In PV $21,000 \mathrm{~W} / \mathrm{m}^{2}$ radiation hits the array for the first 1.5 seconds before falling to $200 \mathrm{~W} / \mathrm{m}^{2}$ until 2.3 seconds when it rises again to $1000 \mathrm{~W} / \mathrm{m}^{2}$. In PV $31,000 \mathrm{~W} / \mathrm{m}^{2}$ radiation hits the array for the first $0.5 \mathrm{sec}$ onds before falling to $600 \mathrm{~W} / \mathrm{m}^{2}$ until 1.5 seconds when it rises again to 1000 $\mathrm{W} / \mathrm{m}^{2}$. In PV $41,000 \mathrm{~W} / \mathrm{m}^{2}$ radiation hits the array for the first 1.0 second before falling to $350 \mathrm{~W} / \mathrm{m}^{2}$ until 2.0 seconds when it rises again to $1000 \mathrm{~W} / \mathrm{m}^{2}$. During

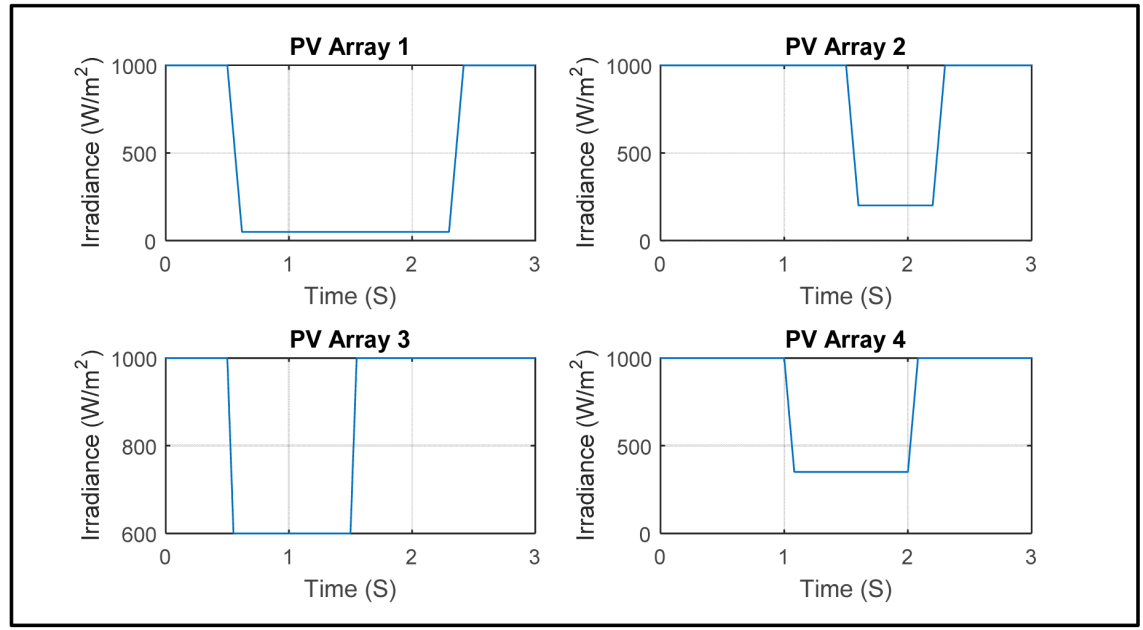

Figure 8. Mean irradiances hitting the PV arrays. 
all simulations, the temperature is kept constant at $25^{\circ} \mathrm{C}$.

Figure 9 shows the voltages produced by each of the $4 \mathrm{PV}$ arrays due to the irradiances shown above; each array is connected to a DC-DC boost converter with maximum power point tracking (MPPT) capabilities, keeping the average voltage at about $250 \mathrm{~V}$ for each array. The blips in the figure correspond to points of changes in irradiances. The maximum voltage produced by each array at any given time is $273 \mathrm{~V}$. This is then boosted to $500 \mathrm{DC}$ by the DC-DC converters.

Figure 10 shows the current outputs from the 4 PV arrays. Since the current generated is directly proportional to the irradiance hitting the arrays, the plots mirror those of the irradiances hitting the arrays.

As with current outputs, power outputs from the $4 \mathrm{PV}$ arrays also mirror the irradiances hitting the arrays as shown in Figure 11. The four power outputs from the PV arrays sum up to the active power injected into the control inverter as shown in Figure 12.

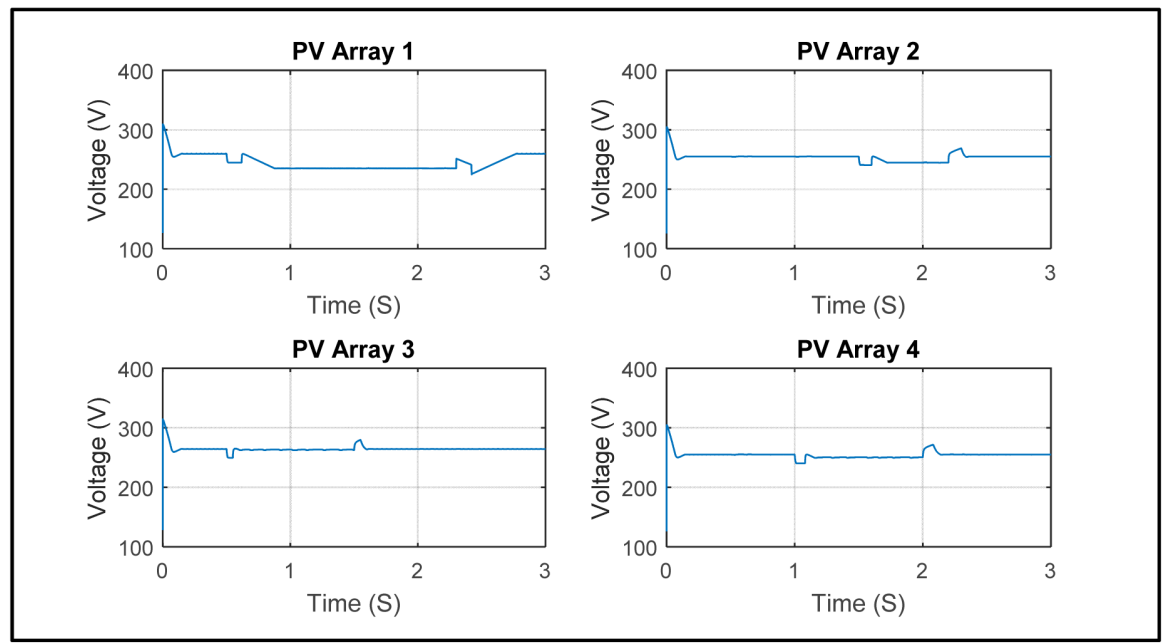

Figure 9. Mean voltages produced by the PV arrays.

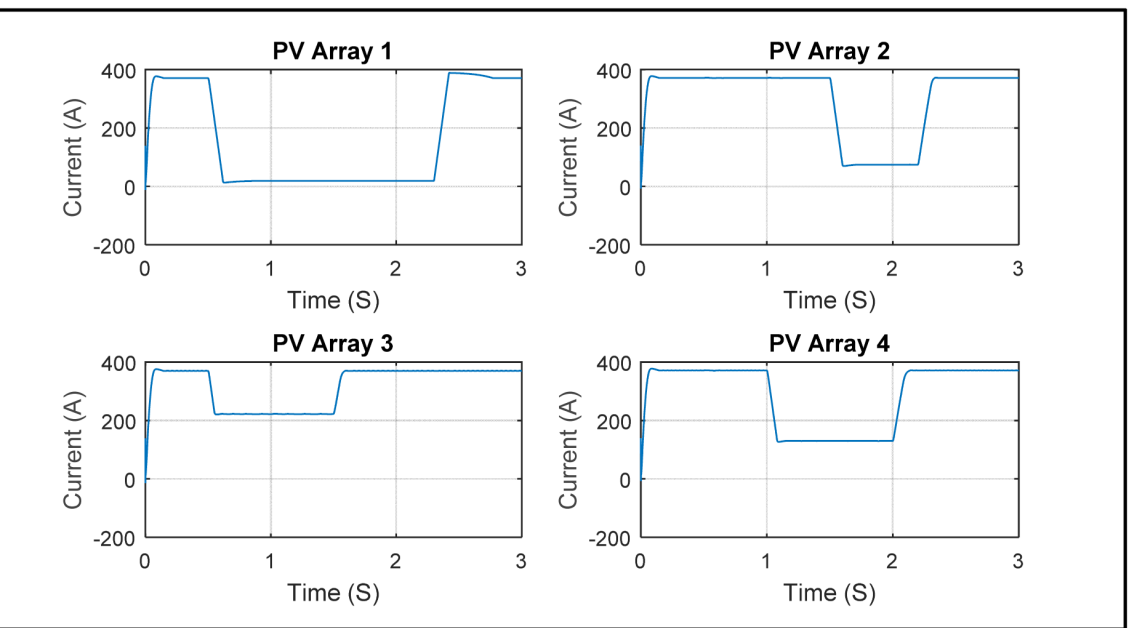

Figure 10. Mean currents generated by the PV arrays. 

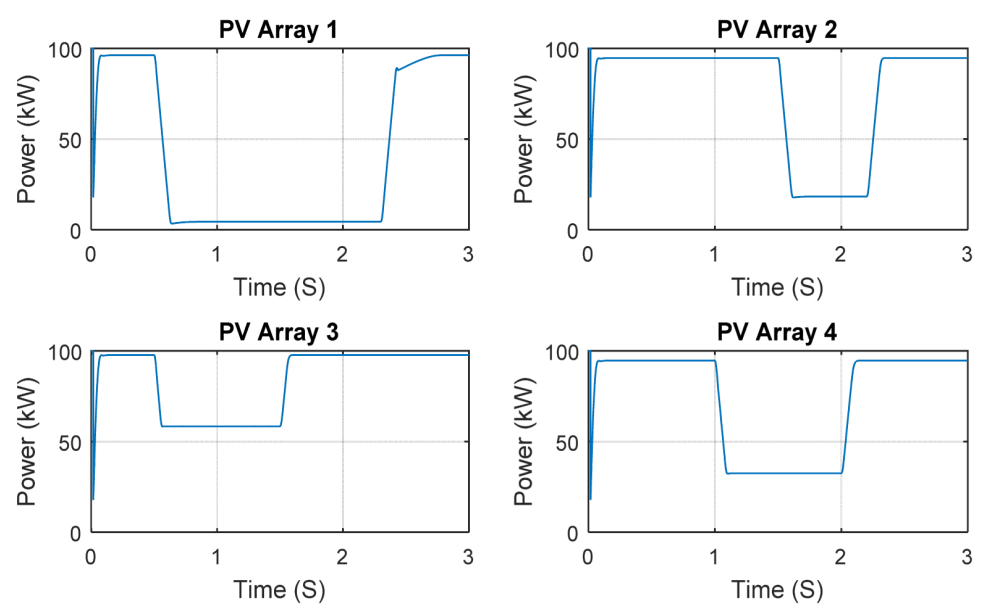

Figure 11. Mean power outputs from the PV arrays.

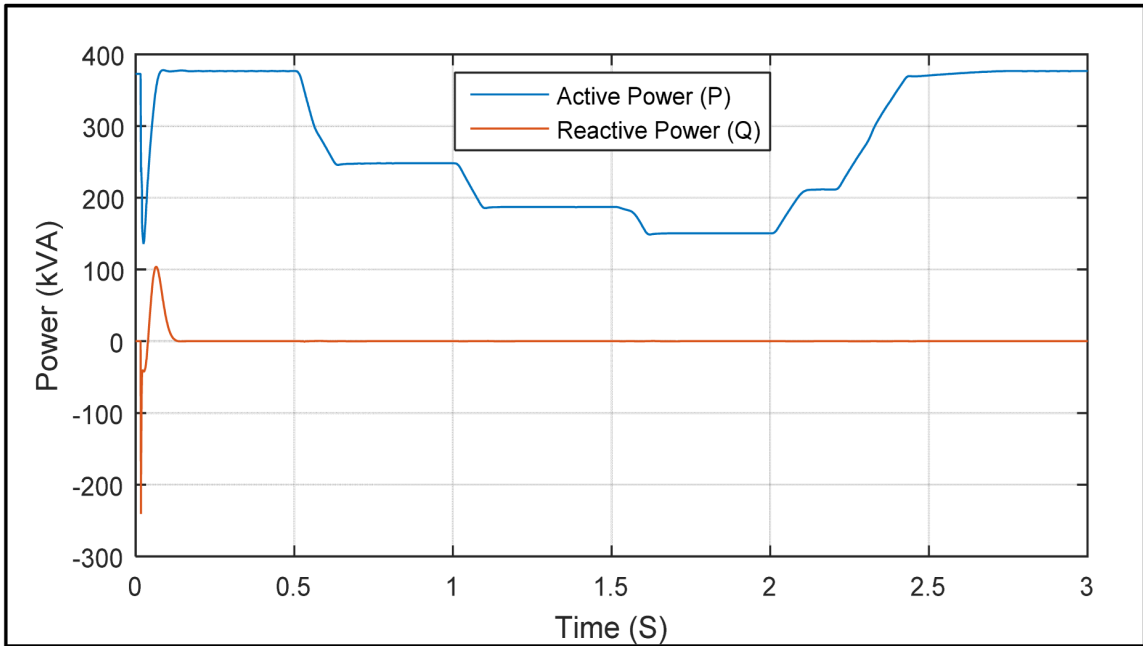

Figure 12. Active and reactive power.

Table 3 shows a comparison of additional power electronics required for different control architectures. From the table, DC-coupled networks with decentralised storage are the cheapest options for rural developing communities, with no additional costs beyond costs common to all other control architectures. These are followed by DC-coupled networks with centralised storage which required additional investments into centralised charge controllers. AC-coupled networks with decentralised storage which need 4 DC-AC inverters come in third, followed by AC-coupled networks with centralised storage which need a central charge controller in addition to the 4 DC-AC inverters. Grid connection requires additional investments for all the networks in forms of VSI, 40-kvar capacitor banks to filter harmonics produced by the VSIs, and 400-kVA $260 \mathrm{~V} / 25$ $\mathrm{kV}$ step-up transformers. It is assumed that all communal grids are initially islanded, and that investments into utility grid connections are made when it finally arrives at a given location. 
Table 3. Comparison of additional power electronics required by networks. (GC is Grid-Connection Cost.)

\begin{tabular}{|c|c|c|c|c|}
\hline \multirow{2}{*}{ Additional Power Electronics } & \multicolumn{2}{|c|}{ Centralised } & \multicolumn{2}{|c|}{ Decentralised } \\
\hline & DC & AC & DC & AC \\
\hline VSI & 1 & 1 & 1 & 1 \\
\hline Central Charge Controller & 1 & 1 & 0 & 0 \\
\hline DC-AC Inverter & 0 & 4 & 0 & 4 \\
\hline Transformer & 1 & 1 & 1 & 1 \\
\hline Filter & 1 & 1 & 1 & 1 \\
\hline Total Additional Cost (\$) & $250+\mathrm{GC}$ & $950+\mathrm{GC}$ & GC & $700+\mathrm{GC}$ \\
\hline
\end{tabular}

Figure 13 shows the view at year after 25 years. The landscape is coloured green with the lighter areas being hill tops. Black houses are those that are unelectrified. Houses deciding on installing PV are coloured white while those that have installed PV are coloured yellow. Houses with PV that meet the communal grid-power-threshold and are deciding on joining communal grids are coloured red. Houses that have joined communal grids are coloured blue and are linked to other houses in the communal grid through grey links (grid lines), from the figure, nearby communal grids join to form even larger regional grids.

\subsection{DC-Coupled Communal Grids}

Figure 14 shows a comparison of households connected to communal grids in centralised and decentralised storage configurations after 25 years while Figure 15 shows their corresponding percentages. After 25 years, 2103 households would have joined communal grids with decentralised storage systems, representing $21.5 \%$ of all households. This is higher than the 1571 households that would have joined networks with centralised storage systems, representing $16 \%$ of all households.

\subsection{AC-Coupled Communal Grids}

Figure 16 shows a comparison of households connected to communal grids in centralised and decentralised storage configurations after 25 years while Figure 17 shows their corresponding percentages. After 25 years, 1887 households would have joined communal grids with decentralised storage systems, representing $19.2 \%$ of all households. This is higher than the 1286 households that would have joined networks with centralised storage systems, representing $13.1 \%$ of all households.

Table 4 shows a comparison of households connected to various grid-connected communal grids after 25 years. Here again it is clear from the table that more households will have joined networks with decentralised storage systems, whether they be DC- or AC-coupled. In the same category, i.e. decentralised or centralised storage, more households would join DC-coupled 


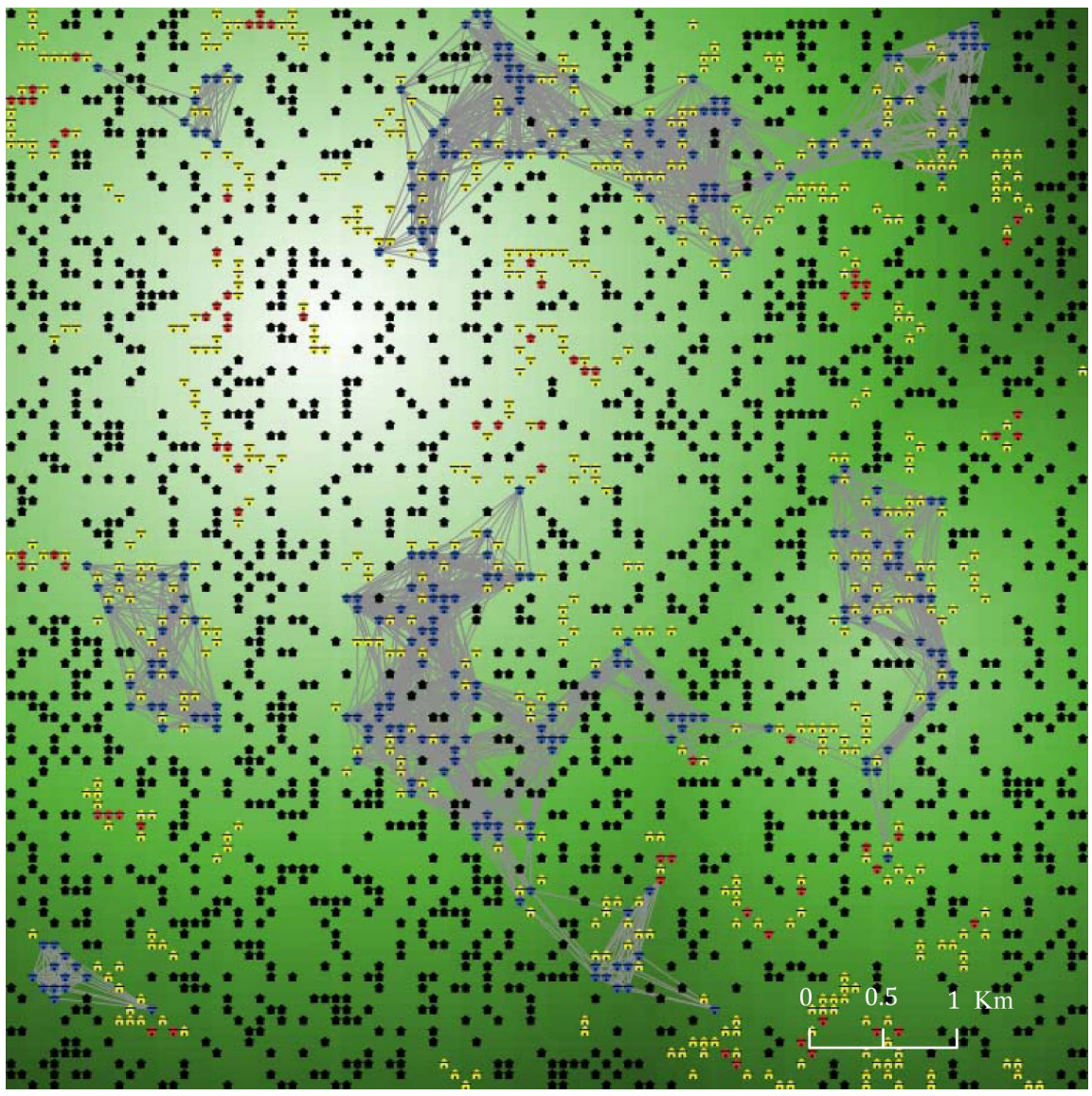

Figure 13. A view of the world after simulations after 25 years.

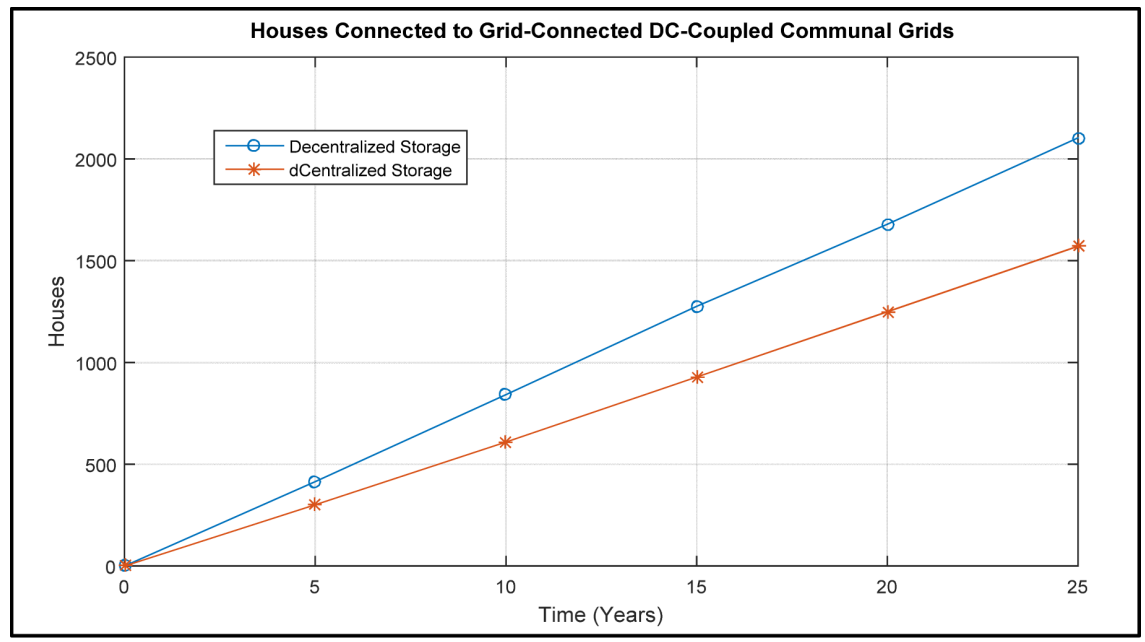

Figure 14. Houses connected to DC-coupled networks.

networks than AC-coupled networks. This is due to additional costs incurred in DC-AC inverter purchases.

\section{Conclusions}

In this work, simulation results from different communal grid architecture 


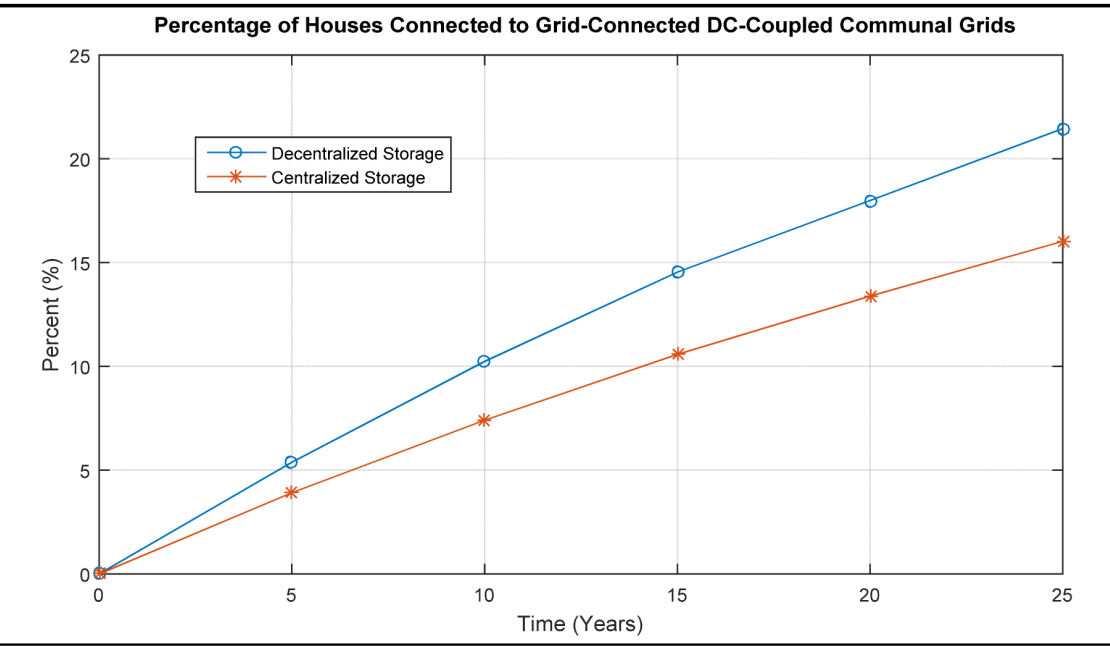

Figure 15. Percentage of houses connected to DC-coupled networks.

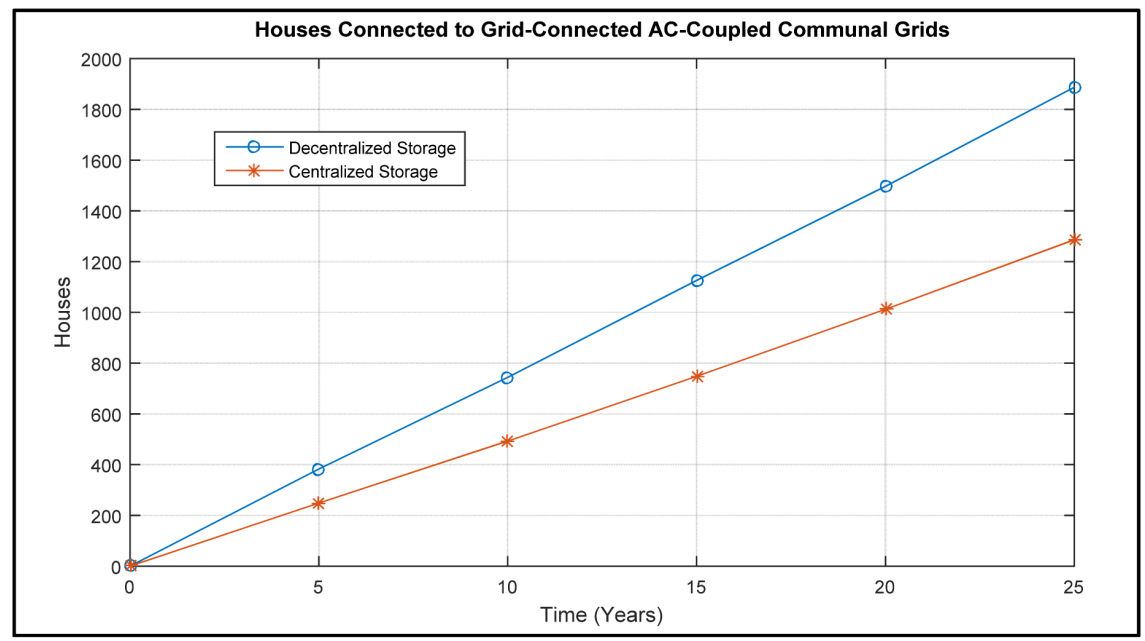

Figure 16. Houses connected to AC-coupled networks.

Table 4. Comparison of houses connected to communal grids under different control architectures.

\begin{tabular}{ccccc}
\hline \multirow{2}{*}{$\begin{array}{c}\text { Time } \\
\text { (Years })\end{array}$} & $\begin{array}{c}\text { Decentralised } \\
\text { Storage }\end{array}$ & $\begin{array}{c}\text { Centralised } \\
\text { Storage }\end{array}$ & $\begin{array}{c}\text { Decentralised } \\
\text { Storage }\end{array}$ & $\begin{array}{c}\text { Centralised } \\
\text { Storage }\end{array}$ \\
\cline { 2 - 5 } 0 & 0 & 0 & 0 & 0 \\
5 & 414 & 301 & 383 & 249 \\
10 & 842 & 609 & 744 & 493 \\
15 & 1276 & 928 & 1126 & 748 \\
20 & 1679 & 1249 & 1497 & 1012 \\
25 & 2103 & 1571 & 1887 & 1286 \\
\hline
\end{tabular}

models developed in MATLAB are fed into an agent-based model developed in NetLogo to determine the most cost-effective option. The novel aspect of this 


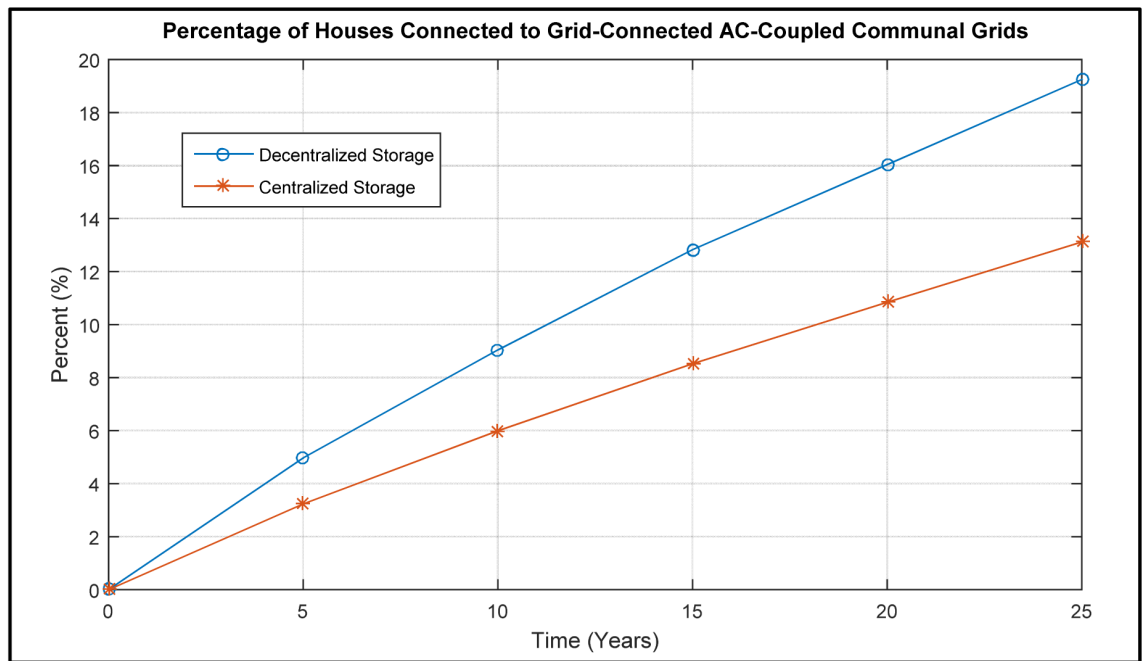

Figure 17. Percentage of houses connected to AC-coupled networks.

paper is that it combines a socio-economic agent-based model with a technical model developed to simulate the most cost-effective communal grid control architecture.

Generally, DC-coupled networks seem to fair better than AC-coupled networks in all categories. This is mainly due to cost and ease of set-up of such networks. As explained above, DC systems tend to be more modular and scalable than AC systems because DC converters are easier to control and to parallel. This allows for more flexibility in system design and expansion, and thus more effective capital investment management. In addition, DC system components tend to be more compact than equivalent AC components because of higher efficiency and by not being frequency dependent. This therefore leads to lower capital costs due to fewer electronic components being used. Moreover, most distributed energy sources and storage devices have inherently DC outputs, making DC architectures more natural options for their integrations. Due to lower power and energy rating, stability issues are more prevalent in communal grids than in utility grids. However, in DC systems where there are no reactive power interactions, there are few stability issues; system control seems to be oriented towards voltage regulation only.

Results show DC-coupled networks with decentralised storage stimulate communal grid connections by allowing easy expansions of the communal grids as each decentralised PV system within a communal grid is treated equally and determines its own real and reactive power, eliminating the need for communication links. This also reduces the cost of implementing such a system; fewer connections are realized with centralised controls as such systems require high speed communication links which make them both difficult to expand and expensive to implement.

Results also show that multi-master operation modes lead to more communal grid connections compared to single-master operation modes because in the 
former, all distributed PV systems within a communal grid have the same rank and can act as masters or can be operated as combinations of master generators (VSIs) and PQ inverters, allowing for more design flexibility and easy connections from potential customers.

In conclusion, for cost-effective communal grids, DC-coupled networks with decentralised storage systems are recommended as the most-cost effective architectures for rural communal grids. Where a communal grid must be AC-coupled communal grids, systems with decentralised storage and multi-master operation modes are recommended for cost-effectiveness.

\section{Acknowledgements}

This research was funded by Leeds International Research Scholarship.

\section{Highlights}

- Decentralised control architectures lead to more connections than centralised controlled;

- DC-coupled communal grids are more cost-effective than AC-coupled ones;

- Combination of DC-coupling and decentralised storage leads to increased PV installations;

- Multi-master operation modes lead to more connections than single-master modes.

\section{Conflicts of Interest}

The authors declare no conflicts of interest regarding the publication of this paper.

\section{References}

[1] International Energy Agency (IEA) (2016) World Energy Outlook.

[2] Zerriffi, H. (2011) Distributed Rural Electrification in Brazil. In: Rural Electrification, Springer, Berlin, 59-87.

[3] Yadoo, A. and Cruickshank, H. (2010) The Value of Cooperatives in Rural Electrification. Energy Policy, 38, 2941-2947.

[4] Reiche, K., Covarrubia, A. and Martinot, E. (2000) Expanding Electricity Access to Remote Areas: Off-Grid Rural Electrification in Developing Countries. Fuel, 1, 1-4.

[5] Short, W., Packey, D. and Holt, T. (1995) A Manual for the Economic Evaluation of Energy Efficiency and Renewable Energy Technologies. National Renewable Energy Laboratory (NREL).

[6] National Renewable Energy Laboratory (NREL) (2012) Energy Analysis: Technology Cost and Performance.

[7] Parshall, L., Pillai, D., Mohan, S., et al. (2009) National Electricity Planning in Settings with Low Pre-Existing Grid Coverage: Development of a Spatial Model and Case Study of Kenya. Energy Policy, 37, 2395-2410.

https://doi.org/10.1016/j.enpol.2009.01.021

[8] Sanoh, A., Parshall, L., Sarr, O., et al. (2012) Local and National Electricity Planning 
in Senegal: Scenarios and Policies. Energy for Sustainable Development, 16, 13-25.

[9] Levin, T. and Thomas, V. (2012) Least-Cost Network Evaluation of Centralized and Decentralized Contributions to Global Electrification. Energy Policy, 41, 286-302. https://doi.org/10.1016/j.enpol.2011.10.048

[10] Foster, V. and Steinbuks, J. (2009) Paying the Price for Unreliable Power Supplies In-House Generation of Electricity by Firms in Africa.

[11] Bhattacharyya, S. and Timilsina, G. (2010) Modelling Energy Demand of Developing Countries: Are the Specific Features Adequately Captured? Energy Policy, 38, 1979-1990. https://doi.org/10.1016/j.enpol.2009.11.079

[12] Urban, F., Benders, R. and Moll, H. (2007) Modelling Energy Systems for Developing Countries. Energy Policy, 35, 3473-3482. https://doi.org/10.1016/j.enpol.2006.12.025

[13] Pecas-Lopes, J., Moreira, C., Mandureira, A., et al. (2005) Control Strategies for Microgrids Emergency Operation. International Conference on Future Power Systems, Amsterdam, 18 November 2005, 6.

[14] Pecas-Lopes, J., Moreira, C. and Mandureira, A. (2006) Defining Control Strategies for Microgrids Islanded Operation. IEEE Transactions on Power Systems, 21, 916-924. https://doi.org/10.1109/TPWRS.2006.873018

[15] Ashbani, S. and Abdel-Rady, M. (2013) General Interface for Power Management of Micro-Grids Using Nonlinear Cooperative Droop Control. IEEE Transactions on Power Systems, 20, 2929-2941. https://doi.org/10.1109/TPWRS.2013.2254729

[16] Bidram, A. and Davoudi, A. (2012) Hierarchical Structure of Microgrids Control System. IEEE Transactions on Smart Grid, 3, 1963-1976. https://doi.org/10.1109/TSG.2012.2197425

[17] De Brabandere, K., Vanthournout, K., Driesen, J., et al. (2007) Control of Microgrids. Power Engineering Society General Meeting, Tampa, 24-28 June 2007, 1-7.

[18] Chowdhury, S., Chowdhury, P. and Crossley, P. (2009) Microgrids and Active Distribution Networks. The Institution of Engineering and Technology, London.

[19] Hatziargyriou, N. (2014) Microgrids: Architecture and Control. John Wiley \& Sons, New York.

[20] Banerji, A., Sen, D., Paul, D., et al. (2013) Microgrid: A Review. Global Humanitarian Technology Conference: South Asia Satellite (GHTC-SAS), Trivandrum, 23-24 August 2013, 27-35. https://doi.org/10.1109/GHTC-SAS.2013.6629883

[21] Baert, D. and Vervaet, A. (1999) Lead-Acid Battery Model for the Derivation of Peukert's Law. Electrochimica Acta, 44, 3491-3504. https://doi.org/10.1016/S0013-4686(99)00117-6

[22] Huang, J., Jiang, C. and Xu, R. (2008) A Review on Distributed Energy Resources and Microgrids. Renewable and Sustainable Energy Review, 12, 2472-2483. https://doi.org/10.1016/j.rser.2007.06.004

[23] Pedrasa, M. and Spooner, T. (2006) A Survey of Techniques Used to Control Microgrid Generation and Storage during Island Operation. 16th Australasian Universities Power Engineering Conference, Melbourne.

[24] Vallve, X. and Serrasolses, J. (1997) Design and Operation of a $50 \mathrm{kWp} \mathrm{PV} \mathrm{Rural}$ Electrification Project for Remote Sites in Spain. Solar Energy, 59, 111-119. https://doi.org/10.1016/S0038-092X(96)00124-7

[25] Opiyo, N. (2016) A Survey Informed PV-Based Cost-Effective Electrification Options for Rural Sub-Saharan Africa. Energy Policy, 91, 1-11.

https://doi.org/10.1016/j.enpol.2015.12.044 
[26] https://ccl.northwestern.edu/netlogo/

[27] Zhao, J., Mazhari, E., Celik, N. and Son, Y. (2011) Hybrid Agent-Based Simulation for Policy Evaluation of Solar Power Generation Systems. Simulation Practice and Theory, 19, 2189-2205.

[28] Opiyo, N. (2015) Modelling PV-Based Communal Grids Potential for Rural Western Kenya. Sustainable Energy, Grids and Networks, 4, 54-61.

[29] Chaurey, A. and Kandpal, T. (2010) A Techno-Economic Comparison of Rural Electrification Based on Solar Home Systems and PV Microgrids. Energy Policy, 38 3118-3129. https://doi.org/10.1016/j.enpol.2010.01.052

[30] D'arco, S., Suul, J.A. and Fosso, O.B. (2015) A Virtual Synchronous Machine Implementation for Distributed Control of Power Converters in SmartGrids. Electric Power Systems Research, 122, 180-197. https://doi.org/10.1016/j.epsr.2015.01.001 